\begin{tabular}{|c|c|c|c|c|c|}
\hline \multirow[t]{2}{*}{ Control variables } & & Percent surveys reporting & Percent surveys reporting & 30-day CABG & 30-day CABG \\
\hline & $\begin{array}{l}\text { Percent surveys reporting 'Yes' to } \\
\text { receiving discharge information }\end{array}$ & 1.000 & $0.555^{*}$ * & $-0.100^{* *}$ & $-0.246^{* *}$ \\
\hline \multirow[t]{2}{*}{- none- $^{a}$} & $\begin{array}{l}\text { Percent surveys reporting 'Strongly Agree' } \\
\text { with understanding care transition }\end{array}$ & $0.555^{*}$ * & 1.000 & $-0.124^{* *}$ & -0.191 * * \\
\hline & CABG case volume & $0.082^{* *}$ & $0.200^{*} *$ & $-0.205^{* *}$ & $-0.100^{* *}$ \\
\hline \multirow[t]{2}{*}{ CABG case volume } & $\begin{array}{l}\text { Percent surveys reporting 'Yes' to } \\
\text { receiving discharge information }\end{array}$ & 1.000 & $0.551^{*}$ * & $-0.085^{*}$ * & $-0.240^{*}$ * \\
\hline & $\begin{array}{l}\text { Percent surveys reporting "Strongly } \\
\text { Agree" with understanding care transition }\end{array}$ & $0.551^{*}$ * & 1.000 & $-0.087^{*}$ * & $-0.175^{*}$ * \\
\hline
\end{tabular}

**. Correlation is significant at $p<0.01$

a. Cells contain zero-order (Pearson) correlations.

mortality after coronary artery bypass grafting (CABG) are two procedure-specific complications Medicare publicly reports. While patient assessments of discharge planning within Hospital Consumer Assessment of Healthcare Providers and Systems (HCAHPS) surveys factor into Medicare hospital reimbursement, their association with outcomes after CABG is unknown.

Objectives We evaluated relationships between HCAHPS patient ratings of care transition and discharge information on 30 day CABG readmissions and mortality.

Methods Data were extracted from Medicare Hospital Compare (July 2018). Pearson and partial correlations measured associations between HCAHPS ratings (percent top-box responses) and morbidity-adjusted CABG mortality and readmissions, controlling for procedure volume. Independent t-tests compared complication rates between hospitals scoring in the top and bottom half on discharge planning ratings.

Results Our analysis included 1017 hospitals with available CABG data. Adjusted for procedure volume, discharge information and care transition ratings negatively correlated with 30 day readmissions $(\mathrm{r}=-0.24, \mathrm{p}<0.001$ and $\mathrm{r}=-0.18, \quad \mathrm{p}<0.001) \quad$ and mortality $(\mathrm{r}=-0.085$, $\mathrm{p}=0.007$ and $\mathrm{r}=-0.087, \mathrm{p}=0.006$ ) (table 1). Readmissions (13.4 per 100 discharges SD1.8 vs 14.01 .9 ) and mortality $(3.1 \% 0.9 \%$ vs $3.3 \% 1.0 \%)$ were lower in hospitals with high ratings of discharge information compared to hospitals with lower ratings $(\mathrm{p}<0.001)$. Readmissions $(13.41 .8$ vs 14.01 .8$)$ and mortality $(3.1 \% 0.9 \%$ vs $3.3 \% 1.0 \%)$ were also lower in hospitals with high care transition ratings $(\mathrm{p}<0.001)$ (figure 1).

Conclusions HCAHPS discharge information and care transition ratings have significant inverse relationships with 30 day CABG mortality and readmissions, even after adjusting for morbidity and volume. Our analysis suggests health literacy at discharge serves as an important benchmark in improving surgical outcomes.

\section{IHI ID 13 CREATING AN INPATIENT OPIOID SAFETY BUNDLE USING MODIFIED DELPHI PROCESS}

Prem Kumar. Health Quality and Safety Commission, New Zealand

10.1136/ihisciabs. 13

Background Opioids are essential medicines for treating pain but are the most common class of medicines that cause harm to inpatients. To address this, The Health Quality and Safety Commission partnered with district health board (DHB) hospitals across New Zealand, in a national formative collaborative to create bundles of care to reduce opioid-related harm.

Objectives To reduce opioid-related harm by $25 \%$ in participating areas of hospitals by April 2016 and develop care bundles to reduce opioid-related harm.

Methods Teams used a modified Delphi process to select the best interventions for the individual harm bundle and the composite care bundle. DHB teams identified the elements (interventions) for the harm bundles. Elements were then reviewed by Delphi panels where members scored the elements based on their suitability for inclusion in an emerging composite care bundle. Inclusion of interventions in the care bundles was based on published evidence, local quality improvement data and expert opinion. The collaboratives expert faculty carried out further Delphi rounds to finalise composite care bundle.

Results Four care bundles were developed, including three care bundles for individual harm areas (opioid-induced constipation, opioid-induced ventilatory impairment and uncontrolled pain) and a composite care bundle (covering all the harms as well as opioid-induced nausea and vomiting), supported by a comprehensive how-to-guide to support further opioid safety work. 7/12 hospitals (58 percent) showed greater than 25 percent relative reduction in opioid-related harm, with 6/12 (50 percent) exhibiting a special cause in statistical process control chart. 
Conclusions Modified-Delphi technique allowed for transparency surrounding consensus and estimated bundle element impact.

\section{IHI ID 14 RATIONAL OPIOID PRESCRIBING}

Adam Ackerman, L Scott Sussman, Deirdre Doyle, Christopher Zematis, Ryan Telford, Anesta Williams, Christine Day, Rockman Ferrigno, David Hajdasz, Bill Sotire, Catherine Fanning, Connie Cholewczynski. Yale New Haven Health, USA

\subsection{6/ihisciabs. 14}

Background At Yale New Haven Health System, our default route for delivering parenteral opioids has previously been the intravenous route, which can increase the risk of hypotension, undesired central nervous system effects and potentially risk of addiction. A multidisciplinary team identified opportunities to modify how opioids are prescribed and administered to reduce the risk of these adverse effects.

Objectives To reduce the number of IV opioid doses administered to adult inpatients, emergency department and observation patients by $25 \%$ through the adoption of a system-wide opioid prescribing standard of practice.

Methods The redesigned practice includes four main principles: EPIC Optimization: The removal of the default route of intravenous delivery of parenteral morphine, hydromorphone and fentanyl orders for adult patients. Education of providers to consider prescribing non-opioid pain medications and/or oral opioids first with subcutaneous delivery as the preferred parenteral route. Education of clinical nurses to consider subcutaneous delivery as the preferred route when parenteral opioids are required and to have a questioning attitude if opioids are routinely prescribed via intravenous delivery. Development of patient education material to provide information about the preferred route for administration of opioids as oral and subcutaneous.

Results Please see the attachment with the data analysis.
Conclusions Our data suggests these interventions were helpful in reducing exposure to IV opioids while still providing effective pain control to hospitalized adults. The work of the team allowed patients to experience consistent delivery of pain medication, better pain control with decreased unwanted side effects.

\section{IHI ID 15 DECREASING LOW-DOSE, RESCUE SEIZURE MEDICATION PRESCRIPTIONS IN NEUROLOGY CLINIC}

Shannon Yarosz, William Parker, Annika Gibson, Anup Patel. Nationwide Children's Hospital, USA

\subsection{6/ihisciabs. 15}

Background Children with seizures who are given incorrect dosing of rescue seizure medications may have a higher risk of emergency department visits, unplanned hospitalizations and even death. As such, it is critically important that children with seizures not only receive timely treatment but also treatment with the correct dose. However, due to a fear of complications, rescue medications are frequently under-dosed (low dose). Low dose treatment is often ineffective in halting seizures.

Objectives Decrease the percentage of low dose prescriptions for rescue seizure medications placed in a Neurology clinic from $3.5 \%$ to $1.5 \%$ by December 2018 and sustain for one year.

Methods We analyzed all rescue medication prescriptions from 2013-2015. We used 2015 data to determine a baseline rate of low-dose prescriptions, while using 2013-2015 data to identify the most commonly miss-prescribed medications. We developed a Key Driver Diagram and implemented the following interventions: Midazolam pre-filled syringe program, standardized dosing, electronic chart alerts, provider education, and pharmacy reviews of each low dose.

Abstract IHI ID 14 Table 1 Control charts and statistical tests: ANOVA comparison and mood test

\begin{tabular}{|c|c|c|c|c|}
\hline & IV Doses & Total MME & Pain Scores & LOS \\
\hline Control Chart Type & X Bar Chart & X Bar Chart & X Bar Chart & X Bar Chart \\
\hline Baseline Performance Mean & 1971.2 & 38409 & 4.68 & 4.67 \\
\hline Baseline Performance $95 \%$ Confidence Interval & $1940.3-2002.2$ & $37873-38945$ & $4.61-4.75$ & $4.57-4.75$ \\
\hline Current Performance Mean & 1150.1 & 28464 & 3.82 & 4.46 \\
\hline Current Performance $95 \%$ Confidence Interval & $1110.7-1189.4$ & $27860-29067$ & $3.79-3.85$ & $4.41-4.58$ \\
\hline Statistical Test & $\begin{array}{l}\text { ANOVA Comparison of } \\
\text { Means, } p=0.000\end{array}$ & $\begin{array}{l}\text { ANOVA Comparison of } \\
\text { Means, } p=0.000\end{array}$ & $\begin{array}{l}\text { ANOVA Comparison of } \\
\text { Means, } p=0.000\end{array}$ & $\begin{array}{l}\text { Moods Test Comparison of } \\
\text { Medians, } \mathrm{p}=0.002\end{array}$ \\
\hline Method for Indicating Out of Control Signals & $\begin{array}{l}\text { Data points that meet ar } \\
1 \text { point }>3 \text { standard dev } \\
9 \text { points in a row on the } \\
6 \text { points in a row all inc } \\
14 \text { points in a row alterr }\end{array}$ & $\begin{array}{l}\text { following criteria are indi } \\
\text { om the center line } \\
\text { de of the center line } \\
\text { r decreasing } \\
\text { and down }\end{array}$ & a red dot on the control & \\
\hline
\end{tabular}

